\title{
PEMANFAATAN MEDIA PEMBELAJARAN GEOBOARD DALAM PEMBELAJARAN MATEMATIKA MATERI KELILING DAN LUAS BANGUN SEGI EMPAT DAN SEGITIGA DI SD NEGERI 1 DESA TEMU KECAMATAN KANOR KABUPATEN BOJONEGORO TAHUN 2017
}

\author{
Novi Mayasari ${ }^{1}$, Nelly Indriastuti P. ${ }^{2}$, Dwi Erna Novianti ${ }^{3}$, Ari Indriani ${ }^{4}$, Ali Noeruddin ${ }^{5}$ \\ ${ }^{1}$ IKIP PGRI Bojonegoro. Email: mahiraprimagrafika@gmail.com \\ ${ }^{2}$ IKIP PGRI Bojonegoro. Email: aisyah.nelly@yahoo.co.id \\ ${ }^{3}$ IKIP PGRI Bojonegoro. Email: dwierna.novianti@gmail.com \\ ${ }^{4}$ IKIP PGRI Bojonegoro. Email: ariindrianiemail@gmail.com \\ ${ }^{5}$ IKIP PGRI Bojonegoro. Email: Ali.ikip.pgri.bojonegoro@gmail.com
}

\begin{abstract}
Mathematics Learning in elementary Schools tends to be difficult to understand about getting up flat. Based on the result of interviews with teachers at SD Negeri 1 Temu Kanor Bojonegoro obtained. The results of student achievement is still below the average value of KKM is $\leq 70$. Therefore more innovative learning media. One of the innovative learning media is Geoboard.Media learning Geoboard is a rigid board that can be used in the learning of class. IV Geometry. This pocked board is simply made of thin wood and then dipak (dipines) in the field.These spikes are arranged so that they are neatly arraged and shaped like square units. The goal of this training is to help students learn mathematics in a fun way so as to create high interest to learn math from an early age. The method of implementation in this community service program is by training method directly to fourth-grade students of elementary school. The result of this training is improvement of student achievement result which can be seen from the average value obtained is $\geq 70$ and the increase of student interest so that more enthusiastic in studying the material of geometry in flat field especially on the subject of searching the circumference and the area of building rectangle and triangle in $S D$ Negeri 1 Temu kanor bojonegoro.
\end{abstract}

Keywords: Media learning geoboard, Learning math.

\begin{abstract}
ABSTRAK
Pembelajaran matematika di sekolah dasar cenderung sulit untuk memahami tentang bangun datar. Berdasarkan hasil wawancara dengan guru di SD Negeri 1 Temu kec Kanor Bojonegoro diperoleh hasil prestasi belajar siswa masih dibawah rata-rata nilai kkm yaitu $\leq 70.01$ eh karena itu diperlukan media pembelajaran yang lebih inovatif. Salah satu media pembelajaran yang inovatif adalah GeoBoard. Media Pembelaaran Geoboard adalah suatu papan berpaku yang dapat digunakan dalam pembelajaran geometri kelas IV. Papan berpaku ini secara sederhana terbuat dari kayu tipis kemudian dipak (dipines) pada bidangnya. Paku-paku (pines) ini disusun sedemikian sehingga tersusun secara rapi dan berbentuk seperti persegi satuan. Tujuan yang ingin dicapai dari pelatihan ini adalah membantu siswa belajar matematika dengan cara yang menyenangkan sehingga tercipta minat-minat yang tinggi untuk belajar matematika sejak usia dini. Metode pelaksanaan pada program pengabdian masyarakat ini yaitu dengan metode pelatihan secara langsung kepada siswa kelas IV Sekolah Dasar. Hasil dari pelatihan ini adalah adanya peningkatan hasil prestasi belajar siswa yang bisa dilihat dari nilai rata-rata yang diperoleh adalah $\geq 70$ dan adanya peningkatan minat siswa sehingga lebih antusias dalam memepelajari materi geometri pada bidang datar khusunya pada pokok bahasan mencari keliling dan luas bangun segi empat dan segitiga di SD Negeri 1 temu kanor Bojonegoro.
\end{abstract}

Kata Kunci: Media Pembelajaran Geoboard, Pembelajaran matematika. 


\section{PENDAHULUAN}

Salah satu cara untuk meningkat mutu pendidikan adalah dengan memperbaiki cara dan metode pembelajaran. Salah satu cara yang bisa ditempuh untuk mampu meningkatkan pembelajaran di kelas khususnya pada mata pelajaran matematika adalah dengan memanfaatkan media pembelajan. Menurut Azhar Arsyad (2011) secara harfiah kata media memiliki arti "perantara" atau "pengantar ". Dan Menurut Basyiruddin Usman Asnawir (2002) pengertian dari Media Pembelajaran adalah segala bentuk fisik yang dapat menyampai-kan pesan serta merangsang peserta didik untuk belajar. Media pembelajaran pun sekarang beraneka ragam jenis, bentuk dan fungsinya. Pendidik atau guru dituntut menjadi kreatif untuk mampu mempersiapkan media pembelajaran yang diperlukan agar peserta didik menjadi lebih mudah memahami materi yang diajarkan.

Selain sebagai media untuk membantu dalam menyampaikan materi pembelaran, media pembelajaran yang dibuat secara menarik mampu menarik minat belajar peserta didik. Sebagai pendidik, guru menjadi fasilitator untuk menyediakan lingkungan belajar yang nyaman untuk peserta didik, dan membantu mereka untuk dapat memahami materi. Salah satu langkah yang bisa dilakukan adalah menggunakan media pembelajaran. Agar pembelajaran di kelas lebih efektif pendidik atau guru bisa memanfaatkan media pembelajaran yang ada, membuat media pembelajaran, atau mungkin menuntun peserta didik agar mampu mengembangakan bakatnya untuk membuat media pembelajaran bagi mereka yang dapat digunakan untuk mereka sendiri.

Anggapan selama ini dari para siswa terkait mata pelajaran matematika adalah ilmu yang sulit, dan sukar untuk dipahami, hal tersebut bisa dilihat dari hasil prestasi belajar siswa yang masih di bawah KKM $\leq 70$. Dan hal ini juga terjadi di tingkat sekolah dasar, salah satunya juga terjadi di SD negeri 1 Temu di kecamatan kanor.

Berdasarkan hasil wawancara denga guru yang mengajar mata pelajaran matematika khususnya di kelas IV di SD Negeri 1 Temu hasil prestasi belajar terutama pada mata pelajaran matematika didapat masih dibawah nilai rata-rata $\leq 70 \mathrm{kkm}$. Melihat kondisi seperti itu kami berinisiatif untuk menggunakan mdia pembelajaran yang lebih inovatif terutama pada pokok bahasan mencari keliling dan luas segiempat dan segitiga, sehingga diharapkan para siswa mampu mengenal bangun datar lebih dalam, akan tetapi banyak kesulitan yang dihadapi dalam pelatihan ini khususnya dalam hal memahami bangun datar dan menentukan luas serta keiling dengan mudah pada bangun datar. Penggunaan metode pembelajaran melalui media pembelajaran Geoboard diharapkan mampu membantu siswa lebih mudah dan senang untuk mempelajari matematika khusunya pada bangun datar. Kegiatan ini juga diharapkan mampu untuk mencetak siswa dengan minat dan kemampuan dalam memecahkan masalah matematika yang memadai untuk tingkatan siswa sekolah dasar.

Sejalan dengan penelitian yang berkaitan dengan luas dan keliling bagun datar. Sesuai dengan penelitian yang dilakukan oleh Sri Wahyuni (2015) dengan judul "Upaya Meningkatkan Hasil Belajar Matematika Menggunakan Alat Peraga Papan Berpaku pada Materi Keliling dan Luas di Kelas III SD Negeri No. 013857 Mekar Baru Kecamatan Kisaran Barat T.A 2014/2015" yang menyimpulkan bahwa penggunaan alat peraga 
papan berpaku dapat meningkatkan hasil belajar matematika siswa pada materi keliling dan luas di kelas III SD Negeri No.013857 Mekar Baru.

Sejalan dengan penelitin yang telah dilakukan oleh Rusli Yatiningsih dan Maryadi, (2010) dengan judul "Meningkatkan Prestasi Belajar Matematika Pada Pokok Bahasan Geometri Melalui Media Geoboard" yang menyimpulkan bahwa hasil penelitian menunjukan bahwa pembelajaran matematika dengan menggunakan media geoboard dapat meningkatkan prestasi belajar matematika pada siswa tunanetra kelas D-2 di SLBA YAAT Klaten.

Berdasarkan penelitian terdahulu yang telah dijelaskan diatas, penelitian ini memiliki kelebihan, di antaranya alat peraga geoboard (papan berpaku) dibuat dengan memberikan beberapa warna agar alat peraga geoboard (papan berpaku) terlihat menarik dan dapat membagkitkan motivasi anak untuk mengikuti proses pembelajaran sehingga hasil belajar siswa menjadi meningkat.

Berdasarkan uraian di atas, peneliti berupaya untuk lebih mengoptimalkan penggunaan media pembelajaran dalam proses pembelajaran di kelas, maka kami berinisiatif dari Dosen Prodi Pendidikan matematika akan mengadakan kegiatan Pengabdian kepada Masyarakat yang akan dilaksanakan di SD Negeri 1 Temu dengan judul "Pemanfaatan Media Pembelajaran GEOBOARD Dalam Pembelajaran Matematika Materi keliling dan Luas bangun segi empat dan segitiga di SD Negeri 1 Desa Temu Kecamatan Kanor Kabupaten Bojonegoro Tahun 2017".

Persoalan yang sama juga dialami oleh SD Negeri II temu rata-rata nilai pelajaran matematika masih di bawah KKM. Hal ini dikarenakan guru masih menggunakan metode ceramah dalam proses pembelajaran. Setelah kegiatan PKM yang kami lakukan ini, Diharapkan sekolah lain terutama jenjang sekolah dasar dapat menggunakan media pemeblajaraan Geoboard dalam proses pembelajaran serta dapat menerpkan media pembelajaran lain yang lebih inovatif sehingga dapat meningkatkan hasil prestasi belajar siswa terutama pada mata pelajaran matematika berikut kami lampirkan profil SD negeri II Temu,

Pada dasarnya Anak-anak pada usia sekolah dasar yang berumur berkisar 6-12 tahun masih sangat akrab dengan dunia bermain, dengan menyediakan media pembelajaran yang akrab dengan dunia mereka akan menimbukan kesan nyaman dan menyenangkan dalam belajar sehinga materi pelajaran bisa diterima dengan baik. Untuk menciptakan kenyamanan dalam belajar pendidik perlu menyediakan media-media pembelajaran yang menyenangkan. Pendidik juga dapat membuat alternatif pembelajaran dengan memberi kesempatan kepada peserta didik agar lebih kreatif lagi dengan membuat media pembelajaran mereka sendiri.Permasalahan yang dihadapi oleh SD Negeri I Temu adalah hasil prestasi belajar siswa yang masih di bawah KKM $\leq 70$, Terutama pada mata pelajaran matematika pada pokok bahasan mencari keliling dan Luas bangun segi empat dan segitiga.

Dan hal sama juga dialami oleh SD Negeri II Temu terutama hasil prestasi belajar siswa yang masih di bawah KKM $\leq 70$, terutama pada mata pelajaraan matemtika. Oleh Karen itu diperlukan suatu terobosan yang baru yang lebih inovatif dengan menggunakan media pembelajaran salah satunya adalah Geoboard. Media pembelajaran 
GeoBoard adalah suatu papan berpaku yang dapat digunakan dalam pembelajaran geometri kelas IV. Papan berpaku (pines) ini secara sederhana terbuat dari kayu tipis kemudian dipaku pada bidangnya. Paku-paku (pines) ini disusun sedemikian sehingga tersusun secara rapi dan berbentuk seperti persegi satuan.

\section{METODE PELAKSANAAN}

Metode pelaksanaan pada program pengabdian masyarakat ini yaitu dengan metode pelatihan secara langsung kepada siswa kelas IV Sekolah Dasar. Adapun tahapan pelaksanaan program yaitu sebagai berikut :

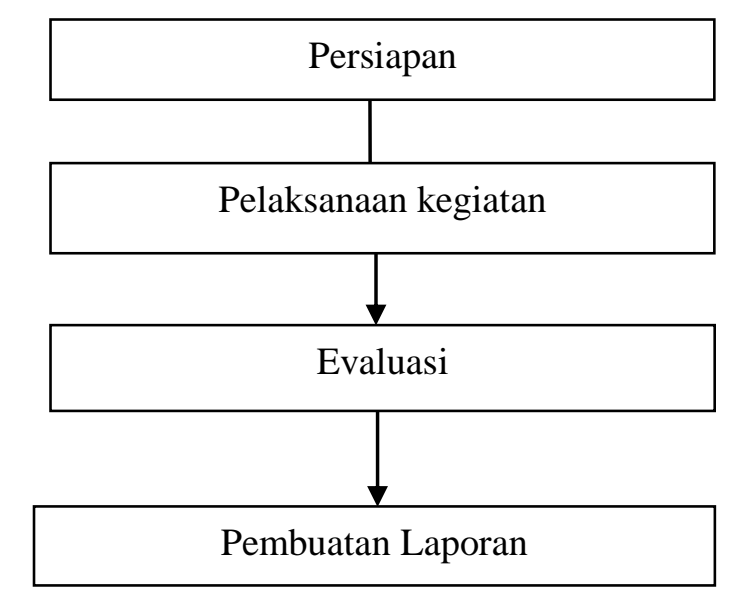

\section{Gambar 1. Diagram Alur Tahapan Pelaksanaan Program}

1. Persiapan

Adapun kegiatan-kegiatan yang akan dilakukan pada tahap persiapan yaitu :

a. Survei tempat pelaksanaan kegiatan

b. Pembuatan proposal dan penyelesaian administrasi untuk program pengabdian masyarakat.

c. Penyiapan alat dan bahan untuk pembuatan media pembelajaran.

2. Pelaksanaan kegiatan

Kegiatan pengabdian akan dilaksanakan setelah semua persiapan sudah selesai dilakukan. Kegiatan akan dilaksanakan di Sekolah Dasar. Dalam pelaksanaanya pemateri memberikan latihan serta cara menggunakan geoboard dalam mata pelajaran matematika dalam materi keliling dan luas bangun datar segiempat dan segitiga.

3. Evaluasi

Evaluasi ini bertujuan untuk melihat perkembangan program yang dilaksanakan, untuk mengetahui kendala yang ada, cara menanganinya sehingga program pengabdian yang dilakukan benar-benar efektif dan maksimal. 
4. Pembuatan Laporan
a. Pembuatan Laporan Awal
Pembuatan laporan awal disesuaikan dengan hasil yang telah dicapai selama melakukan pelatihan penggunaan geoboard.
b. Revisi Laporan
Revisi laporan dilakukan apabila terjadi kesalahan pada pembuatan laporan awal.
c. Pembuatan Laporan Akhir
Pembuatan laporan akhir dilakukan setelah melakukan revisi laporan awal agar dalam penyusunan laporan akhir diperoleh hasil yang lebih baik.

\section{HASIL DAN PEMBAHASAN}

Pembelajaran inovatif dapat dilakukan dengan menggunakan media pembelajaran. Pemanfaatan media pembelajaran dapat membangkitkan keinginan dan minat baru, meningkatkan motivasi dan rangsangan kegiatan belajar, dan bahkan berpengaruh secara psikologis kepada peserta didik (Hamalik, 2004). Dapat dikatakan bahwa suatu pembelajaran yang inovatif dapat meningkatkan motivasi belajar siswa. Oleh karena itu, materi yang diberikan dalam kegiatan ini berkaitan dengan "Pemanfaatan media pembelajaran Geoboard pada mata pelajaran matematika pada pokok bahasan mencari luas bangungn segi empat dan segitiga dan berlangsung di ruang kelas IV SD Negeri 1 temu Kec. Kanor Kab. Bojonegoro. Dari 15 siswa kelas IV dibagi menjadi 5 kelompok yang masing-masing kelompok terdiri dari 3 siswa. Masing-masing kelompok dibagikan alat peraga yang bernama Geoboard. Tiap kelompok diberikan beberapa soal yang berkaitan dengan mencari keliling dan luas bangun segi empat dan segitiga. Bagi kelopok yang bisa menjawab soal akan mendapatkan nilai tertinggi dan mendapatkan reward (hadiah). Dan Hasil Prestasi Siswa dapat dilihat dari tabel 4.1 di bawah ini.

Tabel 4.1 Hasil Prestasi Belajar Siswa

\begin{tabular}{|c|c|c|}
\hline No & Nama & Nilai \\
\hline 1 & Akbar Aji Al Ghazali & 80 \\
\hline 2 & Arjunanto Jati Setiawan & 90 \\
\hline 3 & Dwi Puji Lestari & 70 \\
\hline 4 & M. Arief Ziddane Asfiansyah & 70 \\
\hline 5 & M. Haafid At-Thooriah & 80 \\
\hline 6 & M. Syaiful Huda & 80 \\
\hline 7 & Maya Sri Puji Lestari & 80 \\
\hline 8 & Moh Syahrul Maulidan & 70 \\
\hline 9 & Mohammad Khoirul Anam & 90 \\
\hline 10 & Mukhad Edo Nur Rokhim & 70 \\
\hline 11 & Nur Aurelia & 80 \\
\hline 12 & Nurul Khoirun Nisa & 80 \\
\hline 13 & Ragil Catur Sri Utami & 80 \\
\hline 14 & Yessi nur Sri Juliana & 90 \\
\hline 15 & Yudha Fadilla Dawanus Syifa & 80 \\
\hline
\end{tabular}




\section{SIMPULAN}

Berdasarkan hasil penelitian PKM (Pengabdian kepada masyarakat) yang telah di jabarkan diatas, dapat ditarik kesimpulan dari pembahasan tersebut, diantaranya:

1. Penelitian ini memberikan beberapa materi yang terkait dengan upaya meningkatkan kemampuan siswa SD dalam hal pemanfaatan Geoboard menjadi media pembelajaran Bahasa Inggris yang menyenangkan.

2. Siswa menyambut positif kegiatan ini dan materi yang disajikan dapat dipahami oleh setiap siswa.

3. Para siswa lebih mudah dalam mengerjakan soal mencari luas bangundatar segi empat dan segitiga dengan menggunakan media Geoboard.

4. Kegiatan berlangsung lancar, tepat waktu dan sesuai dengan yang diharapkan.

\section{DAFTAR RUJUKAN}

Arsyad, Azhar. (2011). Media Pembelajaran. Jakarta: PT Raja Grafindo Persada.

Asnawir, Basyiruddin Usman. (2002). Media Pembelajaran. Jakarta: Ciputat Pres.

Hamalik. 2004. Proses Belajar Mengajar. Jakarta: Bumi Aksara.

Wahyuni, Sri. (2015). “Upaya Meningkatkan Hasil Belajar Matematika Menggunakan Alat Peraga Papan Berpaku pada Materi Keliling dan Luas di Kelas III SD Negeri No. 013857 Mekar Baru Kecamatan Kisaran Barat T.A 2014/2015”. (online) http://www.google.co.id/search?q=jurnal+sri+wahyuni+upaya+meningkatkan+has il+belajar+matematika+menggunakan+alat + peraga $+\& b t n G=c l i e n t=\quad m s-o p e r a-$ mini-android diunduh tanggal 05 September 2017.

Yatiningsih, Rusli dan Maryadi. (2010). Meningkatkan Prestasi Belajar Matematika Pada Pokok Bahasan Geometri Melalui Media Geoboard". (online) http://www.slideshare.net/mobile/ichwanAridanu/jurnal-penelitian12060988. diunduh tanggal 05 September 2017. 